\title{
One-year mortality rates after minor and major amputations of the lower limbs
}

Jose M. Pereira de Godoy ${ }^{1}$, Germano Giroldo Tazinaffo ${ }^{1}$, Barbara Lasmine Gomes Abreu Christo ${ }^{1}$, Maria de Fátima Guerreiro Godoy ${ }^{1,2}$

\author{
${ }^{1}$ Department of Cardiology and Cardiovascular Surgery, Medicine School of Sao Jose \\ do Rio Preto, Brazil \\ ${ }^{2}$ Clínica Godoy, Brazil
}

Submitted: 1 May 2021

Accepted: 21 September 2021

Arch Med Sci Atheroscler Dis 2021; 6: e188-e190

DOI: https://doi.org/10.5114/amsad.2021.111314

Copyright @ 2021 Termedia \& Banach

\begin{abstract}
Introduction: Critical limb ischemia is the most severe form of peripheral arterial disease. The anatomic and clinical severity of the disease is often heterogeneous and the choice of treatment is affected by different clinical and patient-related factors. The aim of the present study was to evaluate the mortality rate in a period of 1 year following minor and major amputations and compare the rates with that related to major amputation of lower limbs in 2005.

Material and methods: A cross-sectional study evaluated minor and major amputations of the lower limbs at the School Hospital affiliated with the São Jose do Rio Preto School of Medicine in the period from July 2018 to July 2019. It was conducted using the charts of 233 patients who had undergone minor and major amputations of the lower limbs.

Results: The 1-year mortality rate was analyzed among 108 patients submitted to minor amputations and the mortality rate of 80 patients submitted to major amputations in 2019 was compared to that among 50 patients submitted to major amputations in 2005.

Conclusions: Significant 1-year mortality rates were found following minor and major amputations, with a higher rate among patients submitted to the latter procedure. Moreover, there has been no reduction in the mortality rate among patients submitted to major amputation in the past 15 years.
\end{abstract}

Key words: mortality, minor, major, amputations, lower limbs.

\section{Introduction}

Critical limb ischemia is the most severe form of peripheral arterial disease. It is generally associated with arteriosclerosis, leading to considerable morbidity, mortality, and the loss of quality of life due to disability, which can be aggravated by the occurrence of ischemic ulcers [1, 2]. The anatomic and clinical severity of the disease is often heterogeneous and the choice of treatment is affected by different clinical and patient-related factors [3].

Peripheral arterial disease is underdiagnosed and often unrecognized, affecting around 200 million people throughout the world, one million of whom suffer critical limb ischemia. The 5-year mortality rate after an amputation is $70 \%$, which is twofold higher than the mean 5 -year mortality rate due to cancer in the United States [4]. Researchers report mortality rates of $5.7 \%$ during hospitalization, $15.7 \%$ in the perioperative period, $44 \%$ in the first year, $50 \%$ in the second year, and $72 \%$ in 6 years $[5,6]$.

\author{
Corresponding author: \\ Jose Maria Pereira de \\ Godoy MD, PhD \\ Medicine School \\ of Sao Jose do Rio Preto \\ Brazil \\ Phone: +5517981429814 \\ E-mail: godoyjmp@gmail.com
}


Indications for revascularization treatment in patients with peripheral arterial disease generate considerable discussion and the practice varies significantly among hospitals [7]. Saphenous vein bridging continues to be the gold standard for revascularization in patients with chronic limb-threatening ischemia due to infrainguinal occlusive disease [7]. One study found that saphenous vein bridging resulted in better clinical results compared to endovascular procedures [8].

The aim of the present study was to evaluate the mortality rate in a period of 1 year following minor and major amputations and compare the rates with that related to major amputation of lower limbs in 2005.

\section{Material and methods}

\section{Patients and setting}

The study included one hundred eighty-eight patients who had undergone minor and major amputations of the lower limbs at the School Hospital affiliated with the São Jose do Rio Preto School of Medicine in the period from July 2018 to July 2019 as well as 50 patients who had undergone major amputations in 2005.

\section{Design}

A cross-sectional study was conducted using the charts of 233 patients who had undergone minor and major amputations of the lower limbs. The 1-year mortality rate was analyzed among 108 patients submitted to minor amputations and the mortality rate of 80 patients submitted to major amputations in 2019 was compared to that among 50 patients submitted to major amputations in 2005.

\section{Inclusion criteria}

Patients submitted to minor and major amputations of the lower limbs were included consecutively.

\section{Exclusion criteria}

Disarticulations, upper limb amputations, and amputations due to trauma were excluded.

\section{Randomization}

Patients were selected randomly in the periods of interest until reaching more than 50 individuals in each group.

\section{Development}

Charts of patients submitted to minor and major amputations were analyzed for determination of the 1-year mortality rate between 2018 and 2019. Next, the mortality rate was determined among patients submitted to major amputations in 2005 and comparisons were made between the two periods considering age group and mortality.

\section{Ethical considerations}

This study received approval from the institutional review board of the São Jose do Rio Preto School of Medicine \#461.

\section{Statistical analysis}

The data were tabulated using the Excel program and submitted to statistical analysis. Fisher's exact test was used for the comparisons of prevalence and mortality rates with the aid of the StatsDirect3 program, considering an $\alpha$ error of $5 \%$.

\section{Results}

One hundred eighty-eight amputations (108 minor amputations and 80 major amputation) were analyzed. Mean age among the patients submitted to minor amputations was 64 years for men and 58 years for women. Mean age among those submitted to major amputations was 69 years for men and 72 years for women. The overall mean age at death of patients amputated in 2005 was 67.3 years.

Death occurred within 1 year in $10 / 108$ patients (9.25\%) submitted to minor amputations and $38 / 80$ patients $(47.5 \%)$ submitted to major amputations in 2019. Death occurred within 1 year in $22 / 50$ patients (44\%) submitted to major amputations in 2005 (Table I). Comparing mortality rates among major amputations between the two periods, no significant difference was found ( $p=0.46$, Fisher's exact test).

\section{Discussion}

The present study was conducted at the second largest teaching hospital in Brazil, where approximately 400 minor and major amputations are performed per year on patients with vascular diseases. In the past 35 years, approximately 14,000 amputations have been performed, and the mortality rate of these patients merits attention. Moreover, a reduction in the mortality rate

Table I. One-year mortality rates following minor and major lower limb amputations

\begin{tabular}{|lcccc|}
\hline & Minor amputations & $\begin{array}{c}\text { Deaths following } \\
\text { minor amputations }\end{array}$ & $\begin{array}{c}\text { Major amputations } \\
\text { Deaths following } \\
\text { major amputations }\end{array}$ \\
\hline Total & 108 & $10(9.25 \%)$ & 80 & $38(47.5 \%)$ \\
\hline
\end{tabular}


has been observed in the past 15 years. Mean age at death was 67.3 years in 2005 , whereas mean age is currently 69 years for men and 72 years for women. Therefore, an improvement has occurred in terms of mortality per age. What causes alarm in the present study is that the 1-year mortality rate was $9.25 \%$ among patients submitted to minor amputations and $47.5 \%$ among those submitted to major amputations.

In the comparison of 1-year mortality following major amputations in the 15-year period analyzed, the rate was $44 \%$ in 2005 , which did not differ significantly from the current rate [5]. This suggests that there has been no progress in the reduction of postoperative mortality among patients with chronic arterial disease submitted to major amputations.

Several studies have been conducted by the authors over the years in an effort to better identify factors related to the mortality rates at this institution. One of the studies detected mortality rates of $5.7 \%$ during hospitalization and $15.7 \%$ in the perioperative period [6]. Another important factor was the occurrence of infection due to anaerobic bacteria and multi-resistant germs, in which the overall perioperative mortality rate increased from 15.7\% to approximately $30 \%$ in studies conducted in the past 10 years $[8,9]$. Therefore, preventive measures regarding infection should be more rigorous.

Analyzing the mortality of amputated patients who were discharged from hospital and discarding cardiac causes and readmitted patients, pneumonia was the major cause $(40 \%)$, followed by stroke (12\%) and infections (8\%) [10].

One study found in the literature reports that the mortality rate following lower limb amputations is twofold greater than the rate related to cancer [4]. The present results are compatible with those found in the international literature $[4,11$, 12]. However, these findings serve as a warning and underscore the need for prevention of arteriosclerosis as well as the institution of early treatment for the condition.

Besides mortality, quality of life has been assessed in these patients, revealing an influence not only on physical aspects but also on psychological and social aspects, with a considerable impact on the families of the patients [13]. With regards to coping mechanisms after being informed that amputation would be necessary, a large number of patients sought support in religion, including many of those who previously had no faith [14].

In conclusion, significant 1-year mortality rates were found following minor and major amputations, with a higher rate among patients submitted to the latter procedure. Moreover, there has been no reduction in the mortality rate among patients submitted to major amputation in the past 15 years.

\section{Conflict of interest}

The authors declare no conflict of interest.

\section{References}

1. Serra R, Bracale UM, Barbetta A, et al. PredyCLU: a prediction system for chronic leg ulcers based on fuzzy logic; part II-Exploring the arterial side. Int Wound J 2020; 17: 987-91.

2. Wijnand JGJ, van Koeverden ID, Teraa M, et al. Validation of randomized controlled trial-derived models for the prediction of postintervention outcomes in chronic limb-threatening ischemia. J Vasc Surg 2020; 71: 86979.

3. Benson RA, Meecham LA, Hewitt CA, Bradbury AW. Comparison of immediate and long-term outcomes in men and women undergoing revascularisation for chronic limb threatening ischaemia in the bypass vs. angioplasty in severe ischaemia of the leg (BASIL-1) trial. Eur J Vasc Endovasc Surg 2019; 58: 224-8.

4. Bolíbar I, Gich I, Anglès A, Romero JM, Escudero JR. Variability of revascularization techniques among Catalan hospitals and impact on leg salvage in patients with peripheral arterial disease. Int Angiol 2019; 38: 54-61.

5. de Godoy JM, de Godoy MF, Batigalia F, Trávolo AR, Monteiro EH. Lower-extremity amputation: a 6-year follow-up study in Brazil. J Orthop Surg 2005; 13: 164-6.

6. Pereira de Godoy JM, Ribeiro JV, Caracanhas LA. Major amputation of the lower limbs for critical ischemia. Open Atheroscler Thromb J 2009; 2: 4-5.

7. Star A. Differentiating lower extremity wounds: arterial, venous, neurotrophic. Semin Intervent Radiol 2018; 35: 399-405.

8. de Godoy JMP, Vasconcelos Ribeiro J, Caracanhas LA. Mortality and diabetes mellitus in amputations of the lower limbs for gas gangrene: a case report. Int J Low Extrem Wounds 2008; 7: 239-240.

9. de Godoy JMP, Vasconcelos Ribeiro J, Caracanhas LA, Godoy MFG. Hospital infection after major amputations. Ann Clin Microbiol Antimicrob 2010; 9: 15.

10. de Godoy JMP. Causes of hospitalization among amputees who evolved to death. Int J Med Sci Adv Clin Res 2018; 1: 30-3.

11. Dózsa C, Szeberin Z, Sótonyi P, et al. Az amputációk területi gyakorisága társadalmi és ellátórendszeri összefüggésben Magyarországon 2016-2017-ben [The territorial distribution of amputations in healthcare and social context in Hungary in 2016-2017]. Orv Hetil 2020; 161: 747-55.

12. Minc SD, Hendricks B, Misra R, et al. Geographic variation in amputation rates among patients with diabetes and/or peripheral arterial disease in the rural state of West Virginia identifies areas for improved care. J Vasc Surg 2020; 71: 1708-17.

13. de Godoy JMP, Braile DM, Buzatto SHG, Longo O, Fontes OA. Quality of life after amputation. Psychol Health Med 2002; 7: 397-400.

14. de Godoy JMP, Zanin CR, Fonte OA, Miyazaki MCOS, de Fátima Guerreiro Godoy M. Religious habits of patients submitted to amputation. Acta Angiol 2009; 15 : 30-1. 